\title{
Research on Dynamic Properties of Crane Boom under the Condition of Accidental Unloading
}

\author{
Zhong-Yuan KANG ${ }^{1, a^{*}}$ Ge-Ning XU ${ }^{1}$, Heng YANG ${ }^{1}$, Xin WANG ${ }^{2}$, Jing $\mathrm{LI}^{3}$ \\ ${ }^{1}$ College of Mechanical Engineering, Taiyuan University of science and Technology, 030024 \\ Taiyuan, China \\ ${ }^{2}$ College of Mechanical Engineering, Dalian University of Technology, 116024 Dalian, China \\ ${ }^{3}$ Bery Heavy Industries Co., Ltd, 116024 Dalian, China \\ ${ }^{a}$ kangzhongyuan199@sina.com \\ ${ }^{*}$ Corresponding author
}

Keywords: Effective load, Dynamic characteristics; Rigid-flexible coupling, Multi-body dynamics.

\begin{abstract}
This paper focuses on the special working condition-accidental loss of the effective load of sub-boom working conditions for combined lattice boom, establishes a rigid-flexible coupled model of the sub-boom system based on ANSYS and ADAMS, and applies multi-body dynamics analysis method to conduct theoretical modeling and numerical simulation of unexpected loss of effective load under the two limit working conditions-minimum radius but maximum capacity and maximum lifting moment. Also, the paper studies dynamic response of the structure under the action of vibration and impact excitations, and explores the influence rule of the dynamic performance of the sub-boom system when the effective load loses unexpectedly under different unloading time, lifting ratio and lifting acceleration time. The result of the research indicates that reasonably prolonging the unloading time and lifting acceleration time can contribute to improving the dynamic behavior and service life of the structure as well as properly increasing the lifting ratio.
\end{abstract}

\section{Introduction}

Large space combined lattice cranes, which are favored by all walks of life due to its lighter deadweight, wider working range, larger load-lifting height and other advantages, have played an indispensable role in the development of national economy. For this kind of slender frame structure, it will have a larger elastic deformation when carrying heavy loads. If the effective load loses unexpectedly under the two limit working conditions - minimum radius but maximum capacity and maximum lifting moment, the boom will be very likely to fall backwards, which will result in a serious accident, as a result of rigid body motion and intensive elastic vibration of the lattice boom cranes caused by the transient excitation generated from a sudden release of the gravitational potential energy of effective load and the stored elastic potential energy from the deformation of each flexible part. To avoid this kind of accident, it is necessary to carry on a study on the dynamic response result from accidental loss of effective load which will supply a guide direction for an optimization design of the boom and a reasonable arrangement of the anti-backward-tilting device.

Recently, many scholars have conducted an in-depth research on the dynamic characteristics of the crane boom under the condition of accidental loss of effective load. The ability of the anti-backward-tilting brace is verified by simplifying the mechanical model of the boom under the condition of accidental unloading to single degree of freedom vibration model. Meanwhile, it points out that the magnitude of impact force of the brace mainly depends on the initial position of the boom and the mass of the unloading objects [1].The dynamics model of the complete crawler crane is established by adopting virtual prototyping technology in case that the stiffness of anti-backward-tilting device is variable. By analyzing full dynamic process of back-tipping of the boom, the feasibility of using virtual prototype technology to simulate the dynamic process of the boom is proved [2].A conclusion that the changing trend between hoisting load and buffering power, to a large extent, is linear is made by studying the dynamic behavior of the buffer under the action of impact force generated from sudden unloading based on the method of combining 
rigid-flexible coupling with modal analysis [3]. The previous researches undoubtedly lay a favorable theoretical foundation and technical conditions for the study of dynamic characteristics of the crane boom under the condition of accidental loss of effective load. In response to those circumstances, this paper takes the special condition-accidental loss of the effective load of sub-boom working conditions for combined lattice boom as research object to open up a new way for studying dynamic characteristics of the crane boom under the condition of accidental unloading by using multi-body dynamics analysis method and establishing a reasonable simplified dynamic model.

\section{Theoretical basis}

Rigid multi-body dynamics. The systematic mechanical model is a mechanical abstraction of an actual problem. To carry out dynamic analysis, a systematic mathematical model needs to be obtained from a systematic mechanical model.

Considering that multi-rigid-body system is composed of $\mathrm{N}$ rigid bodies, the generalized coordinate of it is defined as follow:

$$
q=\left[\begin{array}{llll}
q^{1} & q^{2} & \mathrm{~L} & q^{N}
\end{array}\right]^{T}
$$

Supposing that the constraint equation of multi-rigid-body system is as follow:

$$
\Phi(q, t)=0
$$

Where

$$
\Phi=\left[\begin{array}{llll}
\Phi_{1} & \Phi_{2} & \mathrm{~L} & \Phi_{s}
\end{array}\right]^{T}
$$

Then the dynamics equation of the multi-rigid-body system is as follow:

$$
M \ddot{q}+\Phi_{q}^{T} \lambda=Q_{e}+Q_{v}
$$

Where $M=\left[\begin{array}{cccc}M^{1} & & & \\ & M^{2} & & \\ & & \mathrm{O} & \\ & & & M^{N}\end{array}\right]$ is generalized mass matrix, $Q_{e}=\left[\begin{array}{c}Q_{e}^{1} \\ Q_{e}^{2} \\ \mathrm{M} \\ Q_{e}^{N}\end{array}\right]$ is generalized inertial force matrix, $Q_{v}=\left[\begin{array}{c}Q_{v}^{1} \\ Q_{v}^{2} \\ \mathrm{M} \\ Q_{v}^{N}\end{array}\right]$ is generalized active force matrix, $\lambda$ is Lagrangian multiplier.

Flexible multi-body dynamics. For dynamics problems in practical engineering, absolute rigid motion does not exist, and the absolute elastic dynamics problems are also rarely to seen. Multi-rigid-body dynamics is only a simplification of practical engineering problem, and practical engineering problems, seriously speaking; all belong to flexible multi-body dynamics. The dynamic equation of flexible body can be derived from Lagrangian function (Eq. 5):

$$
\left\{\begin{array}{l}
\frac{d}{d t}\left(\frac{\partial L}{\partial \dot{\xi}}\right)-\frac{\partial L}{\partial \xi}+\frac{\partial \Gamma}{\partial \xi}+\left[\frac{\partial \psi}{\partial \xi}\right]^{T} \lambda-Q=0 \\
\psi=0
\end{array}\right.
$$

Where $\psi$ is constraint equation, $\xi$ is the generalized coordinate of a flexible body and $\dot{\xi}$ is the first derivative of $\xi$ versus time, $Q$ is the generalized force projected onto $\xi$, L is Lagrange term defined as $\mathrm{L}=\mathrm{T}-\mathrm{W}$, where $\mathrm{T}$ and $\mathrm{W}$ respectively represents kinetic energy and potential energy, $T=\frac{1}{2} \dot{\xi}^{T} M \dot{\xi}, W=W_{g}+\frac{1}{2} \xi^{T} K \xi$, where $W_{g}$ is the gravitational potential energy of flexible body, $K$ is 
generalized stiffness matrix, $\Gamma$ is energy-loss function, $\Gamma=\frac{1}{2} \dot{q}^{T} D \dot{q}$, where $q$ is the modal coordinate, $\dot{q}$ is the first derivative of $q$ versus time.

By taking $\mathrm{T}, \mathrm{W}$ and $\Gamma$ into Eq.5, the differential equation of motion of the flexible body can be obtained:

$$
M \ddot{\xi}+\dot{M} \dot{\xi}-\frac{1}{2}\left[\frac{\partial M}{\partial \xi} \dot{\xi}\right]^{T} \dot{\xi}+K \xi+f_{g}+D \dot{\xi}+\left[\frac{\partial \psi}{\partial \xi}\right]^{T} \lambda=Q
$$

Where $\ddot{\xi}$ is the second derivative of $\xi$ versus time, $\dot{M}$ is the first derivative of $\mathrm{M}$ versus time, $\frac{\partial M}{\partial \xi}$ is the partial derivative of $M$ versus $\xi$.

\section{Engineering example}

Taking 1900/290t fixed slewing crane provided by an enterprise under the condition of accidental loss of effective load of sub-boom working conditions as an engineering example, the finite element model of 1900/290t fixed slewing crane is shown in Fig. 1. Based on the theory of flexible multi-body dynamics, with virtual prototyping technology as a means, combined with ANSYS and ADAMS, the rigid-flexible coupled model of boom system is built to explore the influence rule of each factor. Since the running time of solving is quite long and the main boom has a relatively larger stiffness due to its parallel double boom so that the vibration of the main boom can be neglected when the effective load unexpectedly loses. Thus, in order to improve the computational efficiency, it is necessary to simplify the model appropriately and solve the sub-boom independently.

Load. Lifting load and overturning load follow GB/T3811-2008 "Design rules for cranes" and ISO8686-1:2012 “Cranes-Design principles for loads and load combinations-Part 1: General” : Before dynamic analysis, dynamic load coefficient $\varphi 9=-0.3$ should be adopted to consider the effect of accident loss of effective load, the load cases are shown in Table 1. Apply overturning load to the axis of the lifting pulley at the head of sub-boom at the moment of unexpected loss of the effective load. The load coefficient 1.5 is the calculation load coefficient when verifying the basic overall anti-overturning stability of the crane, and the load coefficient 1.3 is the calculation load coefficient when verifying the dynamic overall anti-overturning stability of the crane. The self-weight of each component of the boom system is automatically considered when modeling.

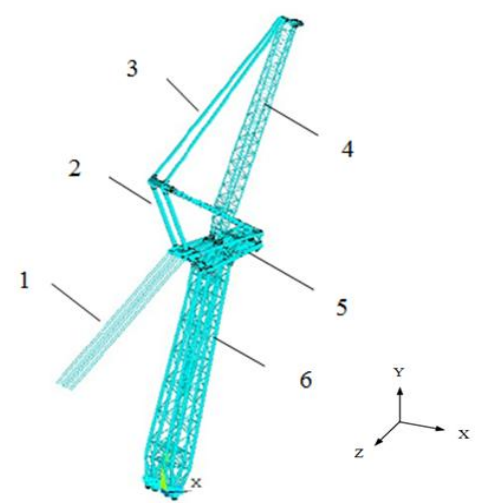

1-Luffing cables 2-A-frame 3-Pull bar of sub-boom 4-Sub-boom 5-Tower head of main boom 6-Main boom

Fig. 1 1900/290t fixed slewing crane

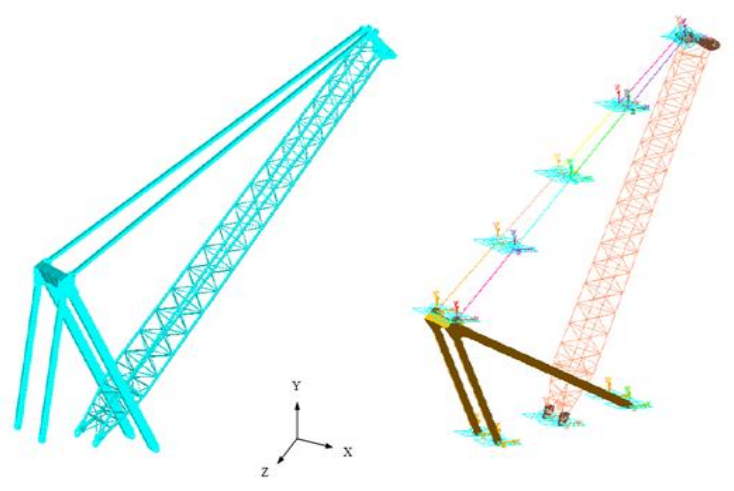

$\begin{array}{ll}\text { (a) Finite element model } & \text { (b) Dynamic model }\end{array}$

Fig. 2. Numerical model of the sub-boom system 
Table 1. Load cases table

\begin{tabular}{|c|c|c|c|c|c|c|}
\hline $\begin{array}{l}\text { Condition } \\
\text { No. }\end{array}$ & Radius /m & $\begin{array}{l}\text { Elevation angle } \\
\text { of main boom } /{ }^{\circ}\end{array}$ & $\begin{array}{c}\text { Elevation angle of } \\
\text { Sub-boom } /^{\circ}\end{array}$ & $\begin{array}{l}\text { Lifting } \\
\text { load/kN }\end{array}$ & $\begin{array}{l}\text { Overturning } \\
\text { load/kN }\end{array}$ & Note \\
\hline 1 & \multirow{4}{*}{38.88} & \multirow{4}{*}{79.8713} & \multirow{4}{*}{74.0840} & $1.5 \mathrm{P}_{\mathrm{Q}}$ & $-0.3 \times 1.5 \mathrm{P}_{\mathrm{Q}}$ & \multirow{3}{*}{$\begin{array}{l}\text { Maximum working } \\
\text { elevation angle }\end{array}$} \\
\hline 2 & & & & $1.3 \mathrm{P}_{\mathrm{Q}}$ & $-0.3 \times 1.3 \mathrm{P}_{\mathrm{Q}}$ & \\
\hline 3 & & & & $\mathrm{P}_{\mathrm{Q}}$ & $-0.3 \times \mathrm{P}_{\mathrm{Q}}$ & \\
\hline 4 & & & & $1.5 \mathrm{P}_{\mathrm{Q}}$ & $-0.3 \times 1.5 \mathrm{P}_{\mathrm{Q}}$ & $\begin{array}{l}\text { Set anti-backward } \\
\text {-tilting device }\end{array}$ \\
\hline 5 & \multirow{3}{*}{63.50} & \multirow{3}{*}{67.3484} & \multirow{3}{*}{61.5611} & $1.5 \mathrm{P}_{\mathrm{Q}}$ & $-0.3 \times 1.5 \mathrm{P}_{\mathrm{Q}}$ & \multirow{3}{*}{$\begin{array}{l}\text { Maximum lifting } \\
\text { moment }\end{array}$} \\
\hline 6 & & & & $1.3 \mathrm{P}_{\mathrm{Q}}$ & $-0.3 \times 1.3 \mathrm{P}_{\mathrm{Q}}$ & \\
\hline 7 & & & & $\mathrm{P}_{\mathrm{Q}}$ & $-0.3 \times \mathrm{P}_{\mathrm{Q}}$ & \\
\hline
\end{tabular}

Multi-Body Dynamics Analysis of The Accidental Loss of Effective Load of the Sub-Boom. In the sub-boom system, comparing with sub-boom and pull bar, A-frame has a relatively bigger stiffness, so we set A-frame as a rigid body model, on the contrary, the sub-boom and pull bar will generate a larger deformation under heavy load due to its fairly larger flexibility, which will lead to a stronger elastic restoring force, so we set sub-boom and pull bar as flexible body model, as a result, the above two model constitute a rigid-flexible coupled dynamic model. The dynamic model is imported into the dynamic simulation software ADAMS through transforming the finite element model (including all interface points) into modal neutral file (.MNF). Meanwhile, A-frame should be set as a rigid body model, as shown in Fig. 2. The constraint condition of each part is shown in Table 2.

Table 2. Constraint condition

\begin{tabular}{|c|c|c|c|c|}
\hline $\begin{array}{c}\text { Sequence } \\
\text { Number }\end{array}$ & $\begin{array}{c}\text { Constraint } \\
\text { component }\end{array}$ & $\begin{array}{c}\text { Constraint } \\
\text { type }\end{array}$ & Number & DOF \\
\hline 1 & Sub-boom & Revolute & 2 & 2 \\
\hline 2 & A-frame & Fixed & 2 & 0 \\
\hline 3 & Pull par & Spherical & 10 & 30 \\
\hline
\end{tabular}

According to the parameter of hoisting mechanism, set the lifting acceleration time to be $10 \mathrm{~s}$ and the unloading time to be $0.1 \mathrm{~s}$ under the condition of unexpected instant loss of effective load. The change of the center of gravity in the $x-y$ plane and the maximum backward angle of sub-boom in different working conditions are shown in Table 3.

Table 3. The change of center of gravity and the maximum backward angle under different working condition

\begin{tabular}{|c|c|c|c|c|c|}
\hline $\begin{array}{c}\text { Condition } \\
\text { No. }\end{array}$ & $\begin{array}{l}\text { The center of } \\
\text { gravity of } \\
\text { sub-boom } \\
\text { X0/m }\end{array}$ & $\begin{array}{c}\text { The center of } \\
\text { gravity of } \\
\text { sub-boom } \\
\mathrm{Y} 0 / \mathrm{m}\end{array}$ & $\begin{array}{l}\text { The center of } \\
\text { gravity of } \\
\text { sub-boom } \\
\text { X1/m }\end{array}$ & $\begin{array}{c}\text { The center of } \\
\text { gravity of } \\
\text { sub-boom } \\
\text { Y1/m }\end{array}$ & $\begin{array}{c}\text { The maximum } \\
\text { backward angle } \\
\theta /^{\circ}\end{array}$ \\
\hline 1 & \multirow{4}{*}{18.7504} & \multirow{4}{*}{91.6054} & 16.6861 & 92.1161 & 4.1459 \\
\hline 2 & & & 17.0752 & 92.0306 & 3.3698 \\
\hline 3 & & & 17.1191 & 92.0201 & 3.2820 \\
\hline 4 & & & 17.1945 & 92.0001 & 3.1302 \\
\hline 5 & \multirow{3}{*}{38.1671} & \multirow{3}{*}{85.3604} & 36.9281 & 85.9817 & 2.7036 \\
\hline 6 & & & 37.0038 & 85.9576 & 2.5497 \\
\hline 7 & & & 37.2223 & 85.8537 & 2.0783 \\
\hline
\end{tabular}

From Table 3, it can be observed that under the same lifting load, as the elevation angle of sub-boom increases, the maximum backward angle enhances; under the same working condition, the maximum backward angle declines with the lifting load reduces. The most dangerous working condition is the Condition No.1 (minimum radius but maximum capacity), the maximum backward 
angle of sub-boom goes to $4.1459^{\circ}$ relative to the working position. The Condition No.5 has been added the anti-backward-tilting device, when the backward angle of sub-boom goes to $3^{\circ}$ to contact with the anti-backward-tilting device, the constant load provided by anti-backward-tilting device $(2 \times 500 \mathrm{kN})$ starts to take effect. Also, the sub-boom continues to rotate backwards, but the peak value is smaller than that in a free state (Condition No.1), which is only $3.1302^{\circ}$, relatively reduced by $24.5 \%$. The maximum impact force of the anti-backward-tilting device is only $52.66 \mathrm{kN}$, far less than $500 \mathrm{kN}$. Thus it can be seen that the anti-backward-tilting device can effectively prevent the back-tipping of sub-boom under the condition of accidental loss of effective load. The impact force of the anti-backward-tilting device is shown in Fig. 3.

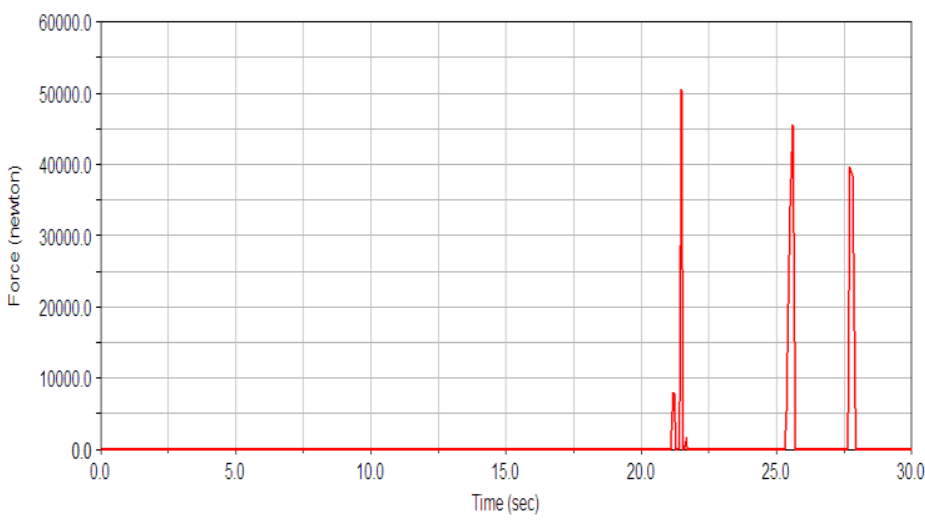

Fig.3. The impact force of the anti-backward-tilting device

Influence rule of unloading time on the dynamic performance of the sub-boom system. The most dangerous working condition - Condition No.1 (minimum radius but maximum capacity) is selected as a research target to explore the influence rule of different unloading time on the dynamic performance of the sub-boom system under the condition of accidental loss of effective load. Set the unloading time to be $0.05 \mathrm{~s}, 0.1 \mathrm{~s}, 1 \mathrm{~s}, 5 \mathrm{~s}$ and $10 \mathrm{~s}$ respectively, the simulation time to be $40 \mathrm{~s}$ and the step size to be 400 .

Table 4.The center of gravity change and the maximum backward angle under different unloading time

\begin{tabular}{|c|c|c|c|c|c|c|}
\hline $\begin{array}{l}\text { Unloading } \\
\text { Time } \\
\text { t/s }\end{array}$ & $\begin{array}{c}\text { The center of } \\
\text { gravity of } \\
\text { sub-boom } \\
\text { X0/m }\end{array}$ & $\begin{array}{c}\text { The center of } \\
\text { gravity of } \\
\text { sub-boom } \\
\text { Y0/m }\end{array}$ & $\begin{array}{c}\text { The center of } \\
\text { gravity of } \\
\text { sub-boom } \\
\text { X1/m } \\
\end{array}$ & $\begin{array}{c}\text { The center of } \\
\text { gravity of } \\
\text { sub-boom } \\
\text { Y1/m }\end{array}$ & $\begin{array}{c}\text { The maximum } \\
\text { backward angle } \\
\theta /^{\circ}\end{array}$ & $\begin{array}{c}\text { The relative } \\
\text { change } \\
\varepsilon / \%\end{array}$ \\
\hline 0.05 & \multirow{5}{*}{18.7504} & \multirow{5}{*}{91.6054} & 16.6547 & 92.1147 & 4.2056 & 0 \\
\hline 0.1 & & & 16.6861 & 92.1161 & 4.1459 & 1.4195 \\
\hline 1 & & & 17.3030 & 91.9753 & 2.9132 & 30.7305 \\
\hline 5 & & & 17.6323 & 91.8977 & 2.2538 & 46.4095 \\
\hline 10 & & & 17.8743 & 91.8381 & 1.7679 & 57.9632 \\
\hline
\end{tabular}

Note: The relative change $\varepsilon$ is benchmarked against the backward angle under the condition that the unloading time is $0.05 \mathrm{~s}$.

As shown in Table 4, under the same working condition, the longer the unloading time is, the smaller the backward angle of sub-boom will be. Therefore, prolonging the sudden unloading time can obviously reduce the vibration and impact of the boom caused by transient excitation generated from the accidental loss of effective load, and can decrease the backward-tilting peak value effectively. Given all that, without affecting the processing technology and performance of the boom, prolonging the sudden unloading time can help to improve the dynamic response characteristics of the boom effectively, which will be beneficial to enhancing the stability and service life of the boom system. Due to the limitation of length, there is only the displacement change curve of the center of gravity of the boom in $x-y$ plane under the condition that the unloading time is $0.1 \mathrm{~s}$, as shown in Fig. 4. 


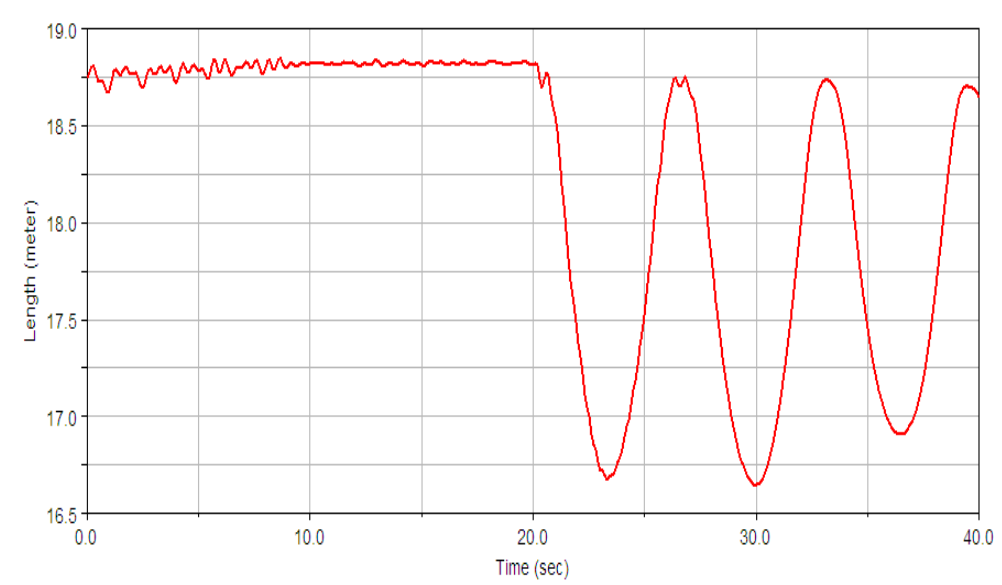

(a) Displacement change curve of $\mathrm{x}$ direction

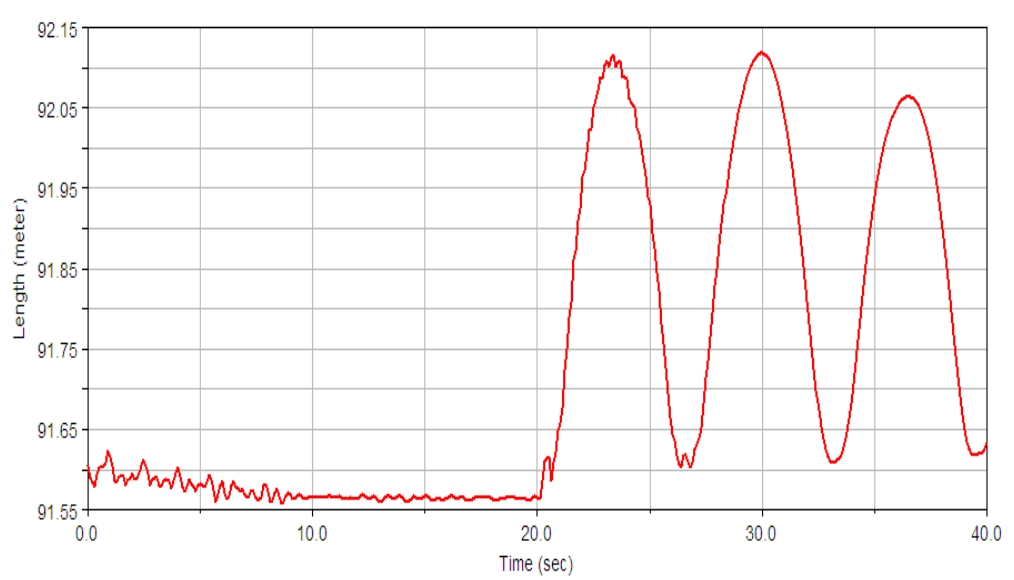

(b) Displacement change curve of y direction

Fig.4. Displacement change curve of the center of gravity of the boom in x-y plane

Influence rule of lifting ratio on the dynamic performance of the sub-boom system. Select the most dangerous working condition-Condition No.1 (minimum radius but maximum capacity) as research target to explore the influence rule of different lifting ratio on the dynamic performance of the sub-boom system under the condition of accidental loss of effective load. Set the unloading time to be $0.1 \mathrm{~s}$, the lifting ratio to be variable which are respectively $2 \times 6,2 \times 7,2 \times 8$ and $2 \times 10$ (double pulley). Also, set the simulation time to be 40 s and the step size to be 400 .

Table 5.The change of the center of gravity and the maximum backward angle under different lifting ratio

\begin{tabular}{|c|c|c|c|c|c|c|c|c|}
\hline $\begin{array}{c}\text { Lifting } \\
\text { ratio }\end{array}$ & $\begin{array}{c}\text { Efficiency } \\
\text { of lifting } \\
\text { pulley } \\
\eta\end{array}$ & $\begin{array}{l}\text { Tension } \\
\text { of lifting } \\
\text { single } \\
\text { rope } \\
\mathrm{T} / \mathrm{kN}\end{array}$ & $\begin{array}{c}\text { The } \\
\text { center of } \\
\text { gravity of } \\
\text { sub-boom } \\
\text { X0/m }\end{array}$ & $\begin{array}{c}\text { The } \\
\text { center of } \\
\text { gravity of } \\
\text { sub-boom } \\
\text { Y0/m }\end{array}$ & $\begin{array}{c}\text { The } \\
\text { center of } \\
\text { gravity of } \\
\text { sub-boom } \\
\text { X1/m }\end{array}$ & $\begin{array}{c}\text { The } \\
\text { center of } \\
\text { gravity of } \\
\text { sub-boom } \\
\text { Y1/m }\end{array}$ & $\begin{array}{c}\text { The } \\
\text { maximum } \\
\text { backward } \\
\text { angle } \theta /{ }^{\circ}\end{array}$ & $\begin{array}{c}\text { The relative } \\
\text { change } \\
\varepsilon / \%\end{array}$ \\
\hline $2 \times 6$ & 0.95 & 376.956 & \multirow{4}{*}{18.7504} & \multirow{4}{*}{91.6054} & 16.4221 & 92.2330 & 4.6919 & 27.7229 \\
\hline $2 \times 7$ & 0.94 & 326.542 & & & 16.6861 & 92.1161 & 4.1459 & 12.8597 \\
\hline $2 \times 8$ & 0.935 & 287.252 & & & 16.8232 & 92.1012 & 3.8781 & 5.5696 \\
\hline $2 \times 10$ & 0.916 & 234.568 & & & 16.9233 & 92.0660 & 3.6735 & 0 \\
\hline
\end{tabular}

Note: The relative change $\varepsilon$ is benchmarked against the backward angle under the condition that the lifting ratio is $2 \times 10$.

From Table 5, it can be seen that under the same working condition and unloading time, the lifting radio increases, but the backward angle of sub-boom decreases with it. The main reason is that with the increase of the lifting radio, the tension of lifting rope decreases, which means that the 
stored elastic potential energy is relatively less; as a result, the transient excitation caused by the elastic deformation of lifting rope is small when the effective load unexpectedly loses. However, larger lifting ratio will disorder the lifting rope under the condition of unexpected loss of the effective load. For this, the advantages and disadvantages of each lifting ratio should be weighed up in order to choose the most favorable lifting ratio. Due to space limitations, Fig. 5 simply includes the displacement change curve of the center of gravity of the boom in $x-y$ plane when the lifting radio is $2 \times 10$.

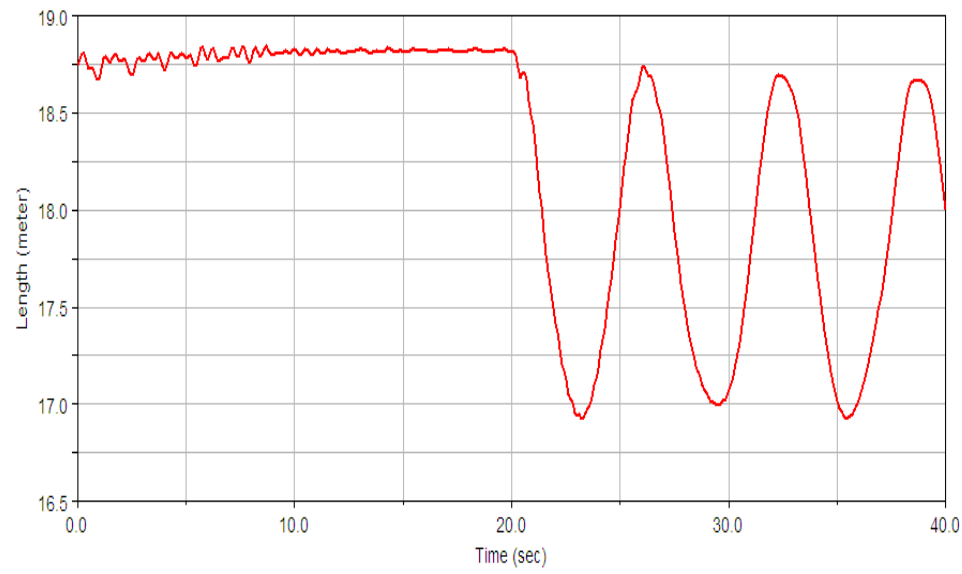

(a) Displacement change curve of $\mathrm{x}$ direction

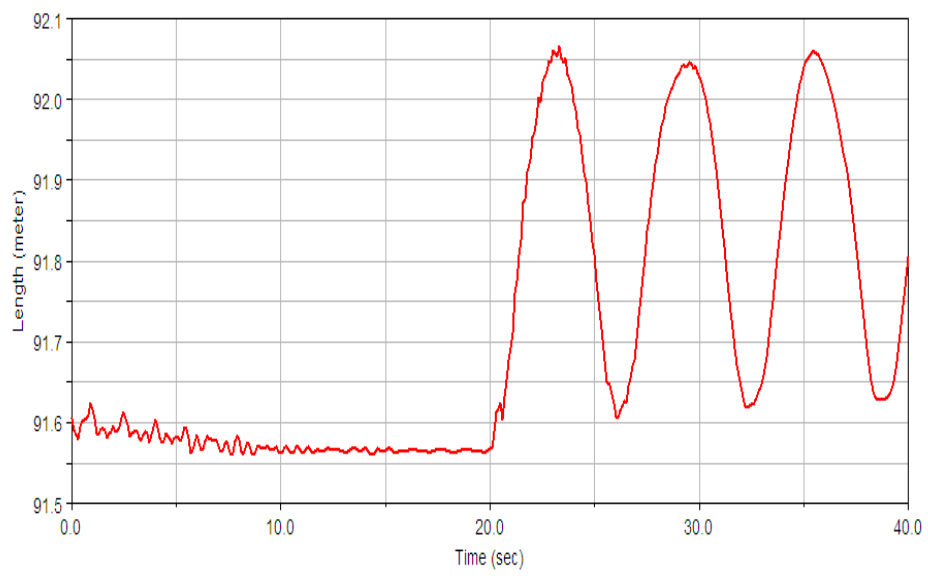

(b) Displacement change curve of y direction

Fig.5. Displacement change curve of the center of gravity of the boom in $x-y$ plane

Influence rule of lifting acceleration time on the dynamic performance of the sub-boom system. The most adverse working condition-Condition No.1 (minimum radius but maximum capacity) is picked out to explore the influence rule of different lifting acceleration time on the dynamic performance of the sub-boom system under the condition of accidental loss of effective load. Respectively set the unloading time to be $0.1 \mathrm{~s}$, the lifting ratio to be $2 * 7$, and the rated speed of lifting mechanism is $34 \mathrm{~mm} / \mathrm{s}$ (refer to the design drawing requirement). Assume that the acceleration characteristic curve of the motor is straight, and take the lifting acceleration time, which are respectively set to be $5 \mathrm{~s}, 10 \mathrm{~s}, 20 \mathrm{~s}$ and $60 \mathrm{~s}$, as a unique variable, the effective load loses at the moment of acceleration to the rated speed. 
Table 6.The change of center of gravity and the maximum backward angle under different lifting acceleration time

\begin{tabular}{|c|c|c|c|c|c|c|}
\hline $\begin{array}{l}\text { lifting } \\
\text { acceleration } \\
\text { time } \mathrm{t} / \mathrm{s}\end{array}$ & $\begin{array}{c}\text { The center of } \\
\text { gravity of } \\
\text { sub-boom } \\
\text { X0/m }\end{array}$ & $\begin{array}{l}\text { The center of } \\
\text { gravity of } \\
\text { sub-boom } \\
\mathrm{Y} 0 / \mathrm{m}\end{array}$ & $\begin{array}{c}\text { The center of } \\
\text { gravity of } \\
\text { sub-boom } \\
\text { X1/m }\end{array}$ & $\begin{array}{c}\text { The center of } \\
\text { gravity of } \\
\text { sub-boom } \\
\text { Y1/m }\end{array}$ & $\begin{array}{c}\text { The maximum } \\
\text { backward } \\
\text { angle } \theta /^{\circ}\end{array}$ & $\begin{array}{c}\text { The } \\
\text { relative } \\
\text { change } \\
\varepsilon / \% \\
\end{array}$ \\
\hline 1 & \multirow{5}{*}{18.7504} & \multirow{5}{*}{91.6054} & 16.1635 & 92.2198 & 5.1833 & 28.2932 \\
\hline 5 & & & 16.3162 & 92.1840 & 4.8785 & 20.7490 \\
\hline 10 & & & 16.6861 & 92.1161 & 4.1459 & 2.6162 \\
\hline 30 & & & 16.6914 & 92.1105 & 4.1336 & 2.3118 \\
\hline 60 & & & 16.7393 & 92.1056 & 4.0402 & 0 \\
\hline
\end{tabular}

Note: The relative change $\varepsilon$ is benchmarked against the backward angle under the condition that the acceleration time is $60 \mathrm{~s}$.

Table 6 indicates that the maximum backward angle of the sub-boom increases as the lifting acceleration time decreases. The relative change $\varepsilon$ of the backward angle under the condition that the lifting acceleration time are $10 \mathrm{~s}$ and $30 \mathrm{~s}$ is not significant comparing with that under the condition of 60s due to the large rated load (397.5t) and small rated lifting speed in Condition No.1. However, when the lifting acceleration time drops to $1 \mathrm{~s}$ and $5 \mathrm{~s}$, the difference swells to 60 times and 12 times respectively comparing with the standard. Meanwhile, the relative change $\varepsilon$ of the backward peak value moves up sharply to $28.2932 \%$ and $20.7490 \%$ respectively.

To sum up, the vibration and impact of the structure, when the effective load unexpectedly loses, can be relieved by prolonging the lifting acceleration time, but the acceleration time is too long to significantly alleviate the impact response of the boom, instead, it will reduce the lifting efficiency. Due to limited space, Fig.6 merely offers the displacement change curve of the center of gravity of the boom in $x-y$ plane under the condition that the lifting acceleration time is $60 \mathrm{~s}$.

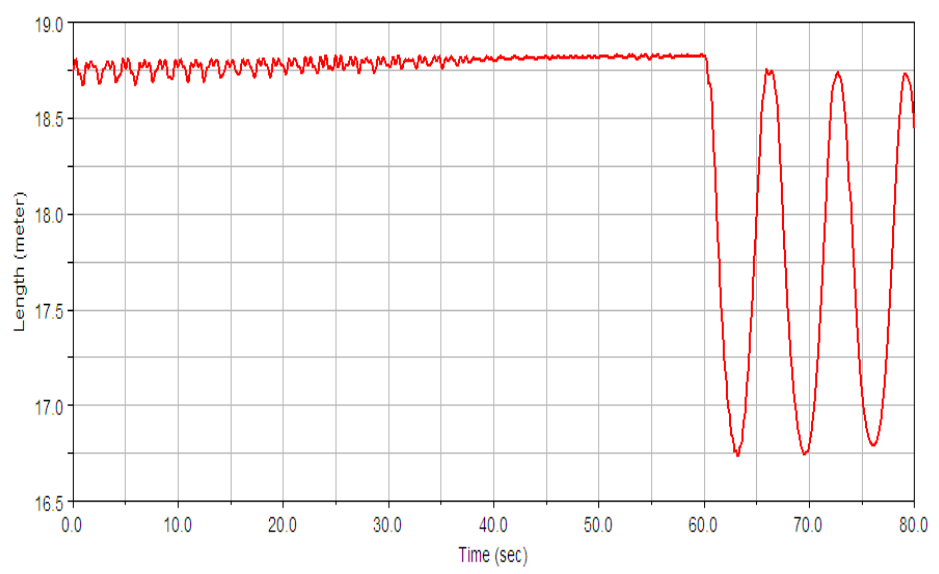

(a) Displacement change curve of $\mathrm{x}$ direction

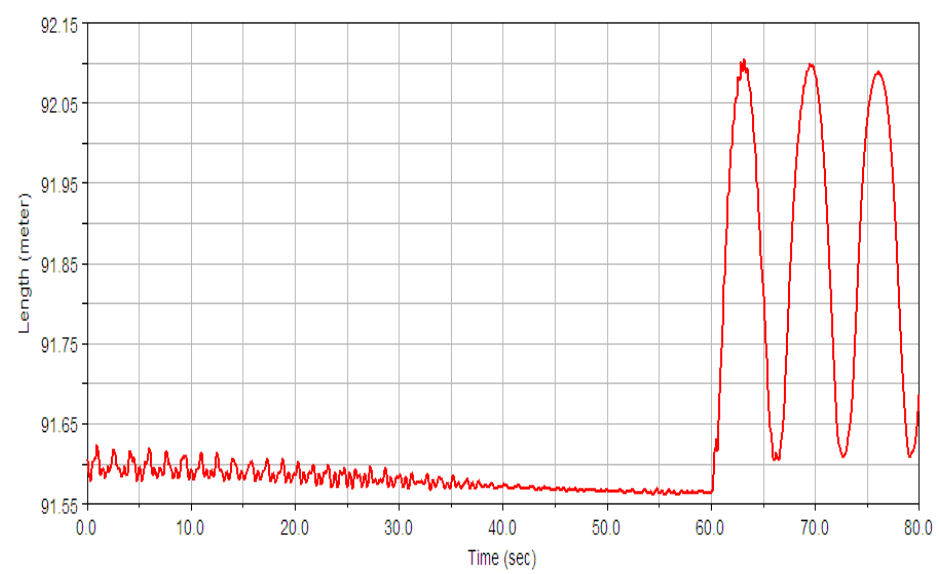

(b) Displacement change curve of y direction

Fig.6. Displacement change curve of the center of gravity of the boom in $x-y$ plane 


\section{Conclusions}

Focus on the special working condition-accidental loss of the effective load of sub-boom working conditions for combined lattice boom and establish a rigid-flexible coupled model of the sub-boom system based on ANSYS and ADAMS, the dynamic response of the structure under the condition that the effective load accidentally loses is studied and the influence rule of different unloading time, lifting ratio and lifting acceleration time and other key parameter on the dynamic performance of the sub-boom system is discussed. Suggestions, which are that reasonably prolonging the unloading time and lifting acceleration time can help to reduce the backward peak value and relieve the dynamic load of the structure under the condition of accidental loss of load under the condition that it has no effect on the processing technology and performance of the boom, are proposed. In addition, properly increasing the lifting ratio can contribute to decreasing the vibration and rebound impact of the boom, and also improving the dynamic behavior and service life of the structure. The above conclusions have reference value for structural design improvements and optimization design.

\section{References}

[1] Tianxing Wu. Dynamic Load Analysis and Calculation of the Anti-backward Device for the Tower Crane, Engineering Machinery, 23-27 (1995)

[2] Junjie Han. Research on the Anti-backward Device of Huge Luffing Jib Tower Crane. Dalian, Dalian University of Technology (2012)

[3] GB/T3811-2008, Design Rules for Cranes, Beijing, Standards Press of China (2008)

[4] Ling Fu, Lekang Yu, Yang Liu, Yin song Li, Jin Zhang. Research on the Unloading Impact Dynamics of the Slender Lattice Crane Boom. Hoisting and Conveying Machinery, 13(1):50-56 (2013)

[5] Xinming Wang. Numerical Analysis of Engineering Structure in Ansys. Beijing, China Communications Press (2007)

[6] Tingzhu Liu, Liqun Chen, WenLiang Chen. Mechanics of Vibration. Beijing, Higher Education Press (2003)

[7] Liping Chen, Yunqing Zhang, Weiqun Ren, Gang Tan. Dynamic Analysis of Mechanical System and ADAMS Application. Beijing, Tsinghua University Press (2005)

[8] GB/T22437.4-2010. Cranes - Design principles for loads and load combinations-Part4: Boom Crane (2010)

[9] GB/T3811-2008. Design Rules for Cranes . Beijing, Standards Press of China (2008)

[10] Gening Xu. Machinery Equipment Metal Structure Design . Beijing, Mechanical Industry Press of China (2009)

[11] ISO8686-1:2012.Cranes-Design principles for loads and loadcombinations-Part1:General (2012) 